\title{
Factors Associated with Self-Esteem, Resilience, Mental Health, and Psychological Self-Care Among University Students in Northern Thailand
}

\author{
Nisarat Auttama' \\ Katekaew Seangpraw (D) $^{\prime}$ \\ Parichat Ong-Artborirak ${ }^{2}$ \\ Prakasit Tonchoy' \\ 'School of Public Health, University of \\ Phayao, Phayao, 56000, Thailand; ${ }^{2}$ Faculty \\ of Public Health, Chiang Mai University, \\ Chiang Mai, 50200, Thailand
}

Background: The severity of mental health issues among university students in rural areas can affect the outcomes of their studies. The purpose of this study was to identify factors associated with self-esteem, resilience, mental health, and psychological self-care among university students. Methods: We conducted a cross-sectional survey of 729 undergraduate students by a selfadministered questionnaire. Using convenience sampling, the participants were chosen from four majoring in Public Health at University of Phayao in Northern Thailand.

Results: Approximately $82 \%$ of university students had mental health problem. Backward logistic regression analysis showed that 1) a good relationship with family had a significantly positive effect on self-esteem ( $p$-value $<0.05)$; 2 ) a good relationship with friends was significantly associated with high resilience ( $p$-value $<0.05$ ); 3 ) having a disease/s and a relationship with family had a significant effect on mental health problem (p-value $<0.05$ ); 4) being female, perceived normal weight, and a good relationship with family were significantly related to high psychological self-care (p-value $<0.05$ ).

Conclusion: Gender, incurrent disease, perceived weight status, relationship with friends and family were associated with self-esteem, resilience, mental health, and psychological self-care among university students. Our findings can be incorporated in a support policy and integrated into the public health curriculum. University administrators and faculty have an opportunity to formulate an intervention program and provide services that could mitigate mental health problems and improve the well-being of students at their university.

Keywords: self-esteem, resilience, mental health, psychological self-care, university students

\section{Introduction}

Mental health disorders is one of the major public health concerns around the world, ${ }^{1}$ particularly among university students, who are more likely than other age groups to experience mental health problems. ${ }^{2}$ According to data from National Statistical Office, adolescents aged 15-24 years had the lowest mental health score, especially in Northern Thailand. ${ }^{3,4}$ The mental health problems such as depression, anxiety, and stress are common in nursing and medical students. ${ }^{5-7}$ In addition, depression is the leading cause of suicide in adolescents. ${ }^{4}$ According to data from Department of Mental Health, the suicide trend in the 20-24-year-old age group was 4.94 per 100,000 people in 2017 , and this number increased to 5.33 per 100,000 people in $2018 .^{4}$ This shows a greater risk of mental health issues among Thai students.
Correspondence: Katekaew Seangpraw School of Public Health, University of Phayao, Phayao, 56000, Thailand Tel + 665446666

Email eungkaew@gmail.com 
Based on a literature review from previous research, many studies show that among the factors that help prevent mental health problems in adolescents are self-esteem and resilience. ${ }^{8-12}$ Self-esteem has the potential to influence individuals' behavioral development. ${ }^{13}$ Having low self-esteem is a root cause of problematic behaviors, such as violence, and the subsequent mental health issues that arise. ${ }^{14,15}$ Self-esteem has been used as a buffer against mental health issues and has demonstrated a positive relationship with students' performances. ${ }^{14,15}$ Resilience is one of the powerful concepts that has been widely adopted and used as a critical preventative measure against mental health problems among adolescents. ${ }^{16}$ According to a literature review from previous research, it was found that social skills have a significant impact on personal resilience. ${ }^{16,17}$ Other studies in China and the United States have found that the higher an individual's personal resilience is, the better that individual can manage mental health problems. ${ }^{18-20}$ Resilience can counteract suicidal ideation among at-risk students. ${ }^{18-20}$

Mental health disorders refer to a wide range of mental health conditions, such as depression, stress, anxiety, and eating disorders. Although many studies have focused extensively on diagnosis and treatment, little attention has been given to preventing or alleviating mental illness among adolescents, especially those who are living and studying in a rural area. It is essential to create awareness of mental health issues, especially among university students. ${ }^{21}$ A previous study has reported a high prevalence of mental distress among university students; moreover, the study found that the factors affecting mental health among students included vulnerability, selfadjustment to coursework, financial problems, a history of mental illness, and relationships with friends and family. ${ }^{21,22}$ These factors had the potential to adversely affect the students' academic performance in university. ${ }^{22}$

A person needs to be aware of his/her own physical and mental health in order to maintain it, and employ selfcare mental health behaviors to cope with mental issues that arise in everyday life. ${ }^{23}$ Adequate self-care behaviors in mental health will enhance an individual's self-esteem and ability to manage stress and anxiety or related mental health problems. ${ }^{23,24}$ Moreover, an individual with a sense of self-esteem will increase his/her strength in dealing with difficulties in life, as a previous study has found. ${ }^{25}$ Other studies have found that self-care behaviors promote mental and physical health and lead to happiness and learning efficiency among adolescents in university. ${ }^{26}$ This study has reviewed research and studies on factors affecting mental health disorders, specifically resilience and psychological self-care; however, no study has focused on university students in rural areas.

Students who are currently studying in the field of health sciences have to focus their academic learning on both theoretical and practical training, as well as in class and in a community; therefore they may experience stress and anxiety which can affect their mental health, leading to lower academic learning efficiency. It is essential for academic faculty and staff to gain knowledge and understanding of mental health issues among adolescents studying at university. The objective of this research was to access factors associated with self-esteem, resilience, mental health, and the psychological self-care of university students in the northern areas of Thailand; moreover, this information will be used to promote a mental health development program, monitor risk factors, and provide assistance to university students.

\section{Methods}

This cross-sectional study was conducted at the Faculty of Medicine, Public Health Department, University of Phayao, Phayao province, Thailand. The study was conducted between July and October 2018. Convenience sampling was employed to select participants for the study. Inclusion criteria were as follows: 1) male or female aged 18-24 years; (2) currently studying in the first to fourth year of university; 3) affiliated with the Faculty of Medicine, Phayao University; and 4) willing to participate in the study. Sample size calculation was based on of Cochran's sample size guidelines [with the formula of the confidence level $=95 \%$, the estimated proportion of the attribute present in the population $=0.5$, the desired level of precision $=0.03 \%$, and population size $=2,000]{ }^{27}$ The researcher added a $10 \%$ drop out rate of the participants to prevent loss of the sample or incomplete data. The total number of undergraduate university students enrolled in the study was 729 .

\section{Instruments Used}

Study measurements were developed and created based on a conceptual framework in order to access and analyze the problems through a five-part questionnaire. The first part of the questionnaire consisted of general information including age, gender, income per month, perceived income sufficiency, current disease/medical history, type of disease, perceived weight status, relationship with 
friends, and family relationship. The second part of the questionnaire was an assessment of a self-esteem questionnaire based on Rosenberg's, ${ }^{24}$ and translated into a Thai version. ${ }^{28}$ The questionnaire included 10 items and a Likert-type scale with items presented on a fourpoint scale, from strongly agrees to strongly disagree; high scores indicated high self-esteem. The questionnaire applied was compatible within the context of the study community. ${ }^{10,21}$ The third part was a Resiliency Interview Form (Life Hardness Assessment) developed by the Corner-Davidson Resilience Scale (CD-RISC-25) (Thai version). ${ }^{29,30}$ The questionnaire was used to assess resiliency in life, and consisted of 25 items, including answers from 0 (not true at all) to 4 (true nearly all the time). High scores indicated high resilience. The fourth part of the questionnaire was the General Health Questionnaire (GHQ: 28) (Thai version) developed to be suitable within the context of university students living in the northern rural area. ${ }^{25,31}$ The questionnaire, which consisted of 28 items, was used as a screening tool to detect those likely to have, or to be at risk of developing, psychiatric disorders and was characterized by two main issues: ability to cope with various problems in life and problems causing distress or an abnormal state in an individual. ${ }^{2}$ The questionnaire covered four areas: 1) somatic symptoms (items $1-7)$; 2) anxiety and insomnia (items 8-14); 3) social dysfunction (items 15-21); and 4) severe depression (items 22-28). The questionnaire was a self-assessment and contained both positive and negative questions, with four choices of answer on a four-point Likert-scale: 1) Not at all, 2) No more than usual, 3) Rather more than usual, and 4) Much more than usual. The score was translated to 0-0-1-1 with a total score of $28 .{ }^{32}$ Scores of 6 and above indicated a mental health problem; however, the score was not able to determine the type of psychiatric disorder. ${ }^{32}$

The final part of the questionnaire was psychological self-care, which covered seven characteristics: 1) selfawareness, 2) effectiveness of the communication, 3) effectiveness of the times, 4) coping with problems, 5) developing and maintaining a social support system, 6) religious activities, and 7) physical self-care. ${ }^{25,26}$ The questionnaire was adapted to be suitable within the context of university students studying in a northern rural area, and consisted of 46 items (Supplementary Table 1). There were four options for the answers to gauge the scale: 1) Never, 2) Sometimes, 3) Rarely, and 4) Every time. The questionnaire contents were examined by three experts from the areas of mental health, adolescence, and public health, and revised before a pilot study was performed on 30 university students. Reliability was analyzed using Cronbach's Alpha Coefficient; the precision of parts 2-5 were $0.82,0.86,0.90$, and 0.86 , respectively.

Data collection was conducted by using a public relations announcement; information relating to the study was posted on the board of the Faculty of Medicine. It provided the objectives, procedures, and benefits of the research. This allowed students to acknowledge the study and decide whether or not to participate. Each participant was given about 30 minutes to respond to the questionnaire. To ensure filling in the questionnaire did not affect the student's study time, they were asked to fill in the questionnaire between 12:00 pm-1:00 pm or 16:00 pm18:00 pm, at their convenience.

\section{Statistical Analyses}

All statistical analyses were completed with SPSS Statistics for Windows Version 17.0, licensed from Chiang Mai University (SPSS Inc., Chicago, IL, USA). Descriptive statistics for the characteristic variables and stress scores are presented using frequencies, percentages, median, and interquartile range (IQR). Median was used to divide the scores of self-esteem, resilience, and psychological self-care into dichotomous variables (low and high groups). The factors associated with self-esteem, resilience, mental health, and psychological self-care among university students were determined by multiple logistic regression using the backward method. The level of significance for statistical tests was set at $p$-value $<0.05$.

\section{Results}

Most of the participants were female $(82.2 \%)$, with males comprising $17.8 \%$ of the sample. The median age was 20 $(\mathrm{IQR}=1)$. More than half of the participants did not have perceived income sufficiency $(54.0 \%)$. In terms of health, a quarter of the participants had an underlying disease/s $(28.0 \%)$; many of these students $(21.0 \%)$ reported having migraine. More than half $(51.7 \%)$ of the participants were of normal weight. In terms of social life, most of the participants had a good relationship with friends and family members $(72.8 \%$ and $69.4 \%$, respectively). Approximately $82 \%$ of university students had mental health problem. General characteristics and the scores of self-esteem, resilience, mental health, and psychological self-care among university students are shown in Table 1.

The effect of general characteristics on self-esteem, resilience, mental health, and psychological self-care 
Table I General Characteristics of University Students (N=729)

\begin{tabular}{|c|c|c|}
\hline Variables & Number & $\%$ \\
\hline \multicolumn{3}{|l|}{ Age (years) } \\
\hline \multicolumn{3}{|l|}{$\operatorname{Min}=18, \operatorname{Max}=24$, Median $=20, I Q R=I(20-2 I)$} \\
\hline \multicolumn{3}{|l|}{ Gender } \\
\hline Male & 130 & 17.8 \\
\hline Female & 599 & 82.2 \\
\hline \multicolumn{3}{|l|}{ Income per month } \\
\hline$\leq 5000$ Baht (USDI58) & 551 & 75.6 \\
\hline$\geq 5000$ Baht (USDI58) & 178 & 24.4 \\
\hline \multicolumn{3}{|l|}{ Perceived income sufficiency } \\
\hline Insufficient & 394 & 54.0 \\
\hline Sufficient & 335 & 46.0 \\
\hline \multicolumn{3}{|l|}{ Incurrent disease/Medical history } \\
\hline No & 525 & 72.0 \\
\hline Yes & 204 & 28.0 \\
\hline \multicolumn{3}{|l|}{ Types of disease $(n=204)$} \\
\hline Migraine & 43 & 21.0 \\
\hline Gastritis & 30 & 14.7 \\
\hline Allergy & 30 & 14.7 \\
\hline Obesity & 30 & 14.7 \\
\hline Hypertension & 22 & 10.7 \\
\hline Depression & 16 & 7.8 \\
\hline Anemia & 15 & 7.4 \\
\hline Muscle weakness & 10 & 5.0 \\
\hline Systemic lupus erythematosus & 8 & 4.0 \\
\hline \multicolumn{3}{|l|}{ Perceived weight status } \\
\hline Thin & 92 & 12.6 \\
\hline Normal & 377 & 51.7 \\
\hline Overweight & 88 & 12.1 \\
\hline Obesity & 172 & 23.6 \\
\hline \multicolumn{3}{|l|}{ Relationship with friends } \\
\hline No good & 198 & 27.2 \\
\hline Good & 531 & 72.8 \\
\hline \multicolumn{3}{|l|}{ Relationship with family } \\
\hline No good & 223 & 30.6 \\
\hline Good & 506 & 69.4 \\
\hline \multicolumn{3}{|l|}{ Self-esteem } \\
\hline Low (scores <26) & 382 & 52.4 \\
\hline High (scores $\geq 26$ ) & 347 & 47.6 \\
\hline \multicolumn{3}{|l|}{ Min $=10$, Max $=37$, Median $=25, I Q R=3(24-27)$} \\
\hline \multicolumn{3}{|l|}{ Resilience } \\
\hline Low (scores <66) & 466 & 63.9 \\
\hline High (scores $\geq 66$ ) & 263 & 36.1 \\
\hline \multicolumn{3}{|l|}{$\operatorname{Min}=48, \operatorname{Max}=82$, Median $=65, I Q R=7(6 I-68)$} \\
\hline Mental health problem & & \\
\hline No $($ scores $<6)$ & 134 & 18.4 \\
\hline
\end{tabular}

(Continued)
Table I (Continued).

\begin{tabular}{|l|c|c|}
\hline Variables & Number & $\%$ \\
\hline Yes (scores $\geq 6$ ) & 595 & 81.6 \\
Min=2, Max=25, Median =10, IQR=7 (7-14) & & \\
\hline Psychological self-care & & \\
Low (scores <88) & 375 & 51.4 \\
High (scores $\geq 88)$ & 354 & 48.6 \\
Min=58, Max=169, Median =87, IQR=14 & & \\
$(8 I-95)$ & & \\
\hline
\end{tabular}

among university students was analyzed using logistic regression (Table 2). Using the backward model, it was found that a good relationship with family had a significantly positive effect on self-esteem (p-value $<0.05$ ). A good relationship with friends was significantly associated with high resilience (p-value $<0.05$ ). Having a disease/s had a significantly positive effect on mental health problem, whereas a good relationship with family had a significantly negative effect on mental health problem ( $p$-value $<0.05$ ). Being female and a good relationship with family were positively related with psychological self-care, whereas perceived thinness, overweight, and obesity were negatively related with psychological self-care (p-value $<0.05$ ). For the analysis, only one of relationship with friends or family was kept due to multicollinearity.

\section{Discussion}

The study showed a very high prevalence $(81.6 \%)$ of mental health problems among university students in northern area of Thailand. A previous study revealed that about $45 \%$ of Thai undergraduate students of Public Health Program in Dental Public Health had mental health problems. ${ }^{33}$ In addition, the findings in our study are higher than that of many studies from other countries. ${ }^{2,34-37}$ The transition to university life can be very challenging for students because they have to face multiple changes, such as coursework, pressure and stress from physical, emotional, and social changes, and adaptation to a new environment. ${ }^{1}$ Mental health problems can negatively affect students mentally and physically, as well as their family members and the nation; therefore, physical, emotional, and environmental adaptation skills are very important and should be taken into account. The importance of social skills should be emphasized and 
Table 2 Backward Logistic Regression Between Predictors and Self-Esteem, Resilience, Mental Health, and Psychological Self-Care of University Students $(\mathrm{N}=729)$

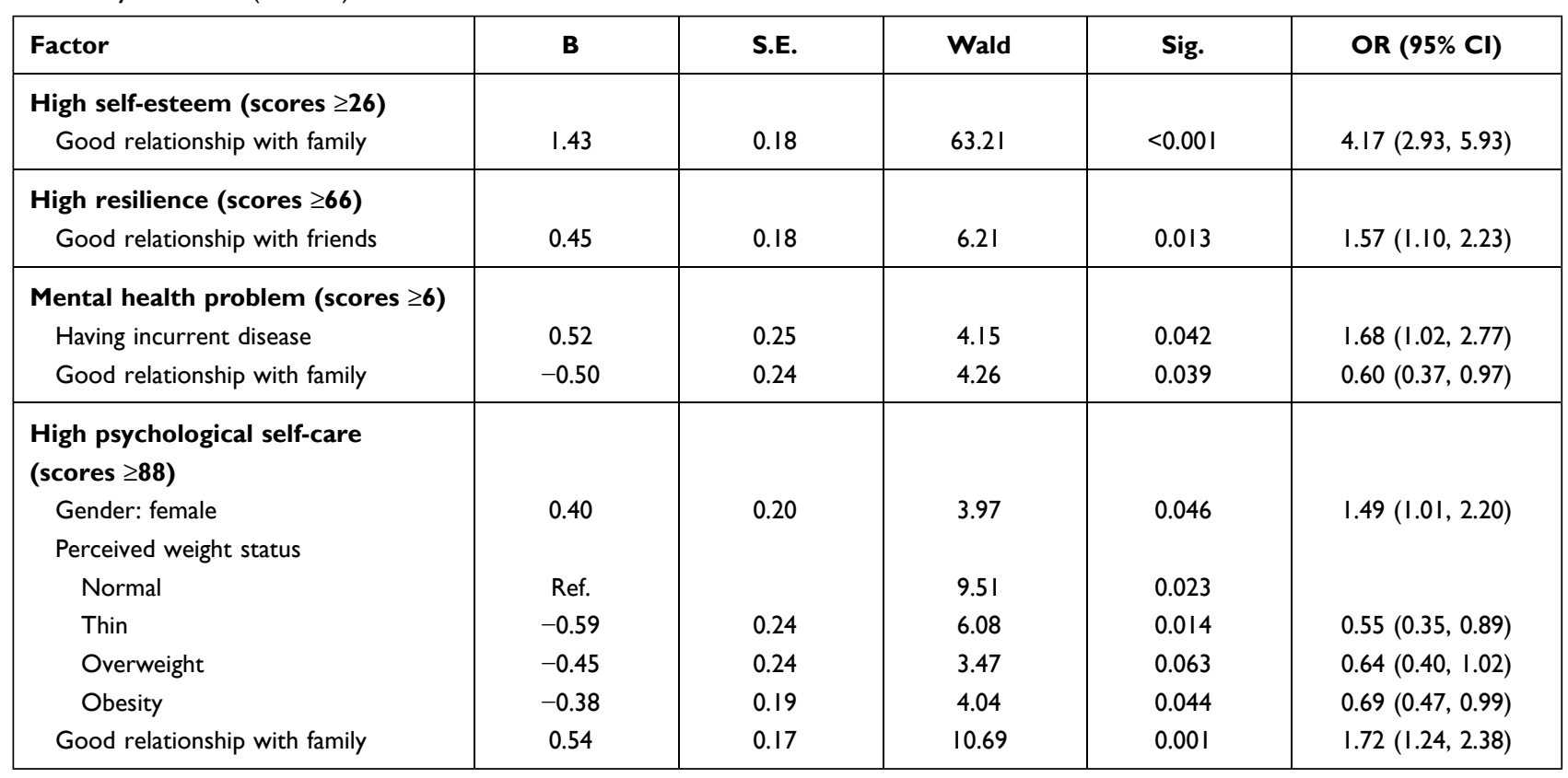

Abbreviations: B, regression coefficient; S.E., standard error; OR, odds ratio; $\mathrm{Cl}$, confidence interval; Ref., reference group.

should be taught to improve their ability to cope with problems related to mental health and social life. ${ }^{17}$ The mental health conditions of each individual vary considerably depending on parenting style, learning experience and problem-solving skills in life. ${ }^{1,9}$ The findings of this research will be used as baseline information to develop a mental health program in order to reduce mental health problems among university students in the study area. It is very important for executive board, administrators, and faculty members to focus on improving the curriculum, integrating a teaching and learning atmosphere, providing mental health assistance to prevent mental health problems and to improve the health and well-being of students studying in the university. As an educational institution, it is very important to help students meet their full potential by providing an environment that is safe, supports their ideas, provides access to hands-on activities, and promotes respect for all people and things.

In our study, there was a statistically significant association between a good relationship with family and high self-esteem. This is consistent with a previous research which found that family relationships have a positive association with self-esteem; the students from harmonious families were higher on self-esteem than those from the conflicting families. ${ }^{38}$ Another study showed that environmental factors such as social status, including relationships with friends and family, are associated with self-esteem. ${ }^{39}$ Also, physical and emotional abuse by parents or other adults in the household was a major risk factor associated with low self-esteem. ${ }^{40}$ A parent-child relationship may indirectly affect academic stress through self-esteem. ${ }^{41}$ Maintaining good social relationships can lead to higher self-confidence among individuals. ${ }^{14,42}$

Our study found that social relationships were significantly associated with resilience. This is similar to the findings of previous studies which established that relationships with peers and social support are positively correlated with strength in life. ${ }^{43,44}$ This can be explained by the fact that a person's self-worth is one of the factors that contributes to a person's strength in life. ${ }^{45}$ Moreover, interpersonal relationships are among the factors that encourage adolescents to adapt to a new environment and to increase strength in life. ${ }^{46}$ Students who have good relationships with friends are more likely to have strength in life because they want to be part of a group, to be accepted by peers, and to be able to share their thoughts and problems with someone. Accordingly, having a good social relationship is key to increasing a person's confidence and self-worth. ${ }^{39,46}$ Therefore, individual resilience involves social support, health behaviors, social acceptance, and personal actions that promote well-being and mental health. ${ }^{47}$ 
In terms of mental health problems, it was found that having incurrent disease and a poor relationship with family had a significant relationship with poor mental health. This is consistent with a previous study, which found a relationship between a relationship within family and mental health status in first year undergraduate students. ${ }^{48}$ Negative life events such as conflicts with parents, and health problems caused emotional stress of the Faculty of Nursing Students in university. ${ }^{6}$ A previous study reported that $17.8 \%$ of university students who had underlying disease experienced anxiety and stress, which impacted their academic training, resulting in physical exhaustion and severe mental health problems. ${ }^{25}$ Another study showed that orphans with underlying disease were at higher risk of developing mental health problems $(17.6 \%) .{ }^{49}$ This corresponds to studies in Turkey and Guinea that found that orphans with chronic diseases experienced negative impacts on their mental health; they were also at risk of developing psychiatric disorders. ${ }^{50,51}$ Another study showed that mental health had a positive correlation with chronic illnesses among pharmacy students. ${ }^{52}$ Quite clearly, poor health conditions can lead to poor mental health such as anxiety and stress. Once physical exhaustion occurs, the body and mind automatically react to stress. A person may experience various symptoms including nausea, vomiting, decreased memory, or a lack of consciousness. A person who is unable to face and manage problems over a long period tends to develop stress and anxiety, resulting in poor mental health and well-being. ${ }^{50,52}$

In terms of psychological self-care, factors such as gender, relationship with family, and perceived weight status had a statistically significant relationship with psychological self-care. Similar to a previous study, females are more likely to practice self-care for mental illness treatment than men. ${ }^{53}$ Students with perceived thinness or obesity have poor self-care behaviors in relation to mental health; this finding is similar to a study which showed students who perceived health had stress and poor health management; and students who were overweight had negative self-care behaviors. ${ }^{25}$ Having health problems may affect a person's mental health care. ${ }^{54}$ The study found that good social relationships among friends and family had a positive effect on psychological self-care. Another study found that participants who had good relationship with peers and communicated with their class members demonstrated quality self-care toward themselves and maintained good mental health, leading to improved mental health. ${ }^{25,26}$ Maintaining good relationships with friends and family has a positive correlation with students' academic performance, happiness, and selfcare behaviors. ${ }^{26}$ Also, a person's background factors had an impact on his/her degree of self-care. ${ }^{23}$ In this study, the participants were students currently studying at university. In this phase of their lives which marks the transition from adolescence to adulthood, the students experience changes in many situations, including environmental and social adaptation, learning about and establishing relationships with peers, and developing physically and mentally; therefore, taking good care of one's health based on the principles of good mental health is important for a person to realize self-worth, have the ability to cope with problems, and to communicate. ${ }^{25,55}$

\section{Limitations}

There are several limitations in this study. First, the results of this study cannot be generalized and represented as a whole population because the participants were drawn from a group of public health students at one university, and were selected by convenience sampling, making a small number of males. Further research should be performed with more than one university by probability sampling to generalize the findings and be able to initiate a common approach for solving and preventing mental health problems among university students at the educational institution level. Second, information such as perceptions toward mental health, self-care behaviors toward physical and mental health, other psychosocial and sociodemographic factors (history of mental illness, family history of mental illness, history of drug misuse, and recent stressors) were not mentioned in this study; however, these areas should be included in future studies. Third, data collection was performed a month before the final exam. This may have placed stress or anxiety on the students more than any other period of time. In order to obtain accurate data, data collection should be performed over different periods so that the researcher can see the difference of results through time. Fourth, data collection was done by the researcher and the researching team who are instructors at the university. Because of this, the students may have been anxious in responding to the questions and not been entirely truthful, or they may have withheld relevant information from the research. To solve this issue in future research, those who distribute the questionnaire should be people from outside the faculty of the 
university. Fifth, students who enroll at the university are from different parts of Thailand, and their family and cultural backgrounds vary depending according to where they are from and how they have experienced life. This study has insufficient qualitative information such as psychosocial factors; therefore, the researcher may not know each individual's background information well. In addition, qualitative information should be employed to gain insights into these students' mental health and wellbeing. Lastly, data collection was done through selfassessment; and the questionnaire used was just a baseline screening assessment. Students have to be diagnosed by a psychiatrist in order to clinically prove whether or not they have a mental health disorder; the process includes assessing the students' history of mental health and conducting a physical and mental examination. However, this research has indicated that mental health problems are found among public health students and that several factors affect their mental health. Self-esteem and resilience are among the main predictors of mental health among university students. Moreover, self-esteem and resilience play a major role in improving mental health among university students, leading to improved selfdevelopment and a sense of personal self-esteem.

\section{Conclusion}

Mental health issues among university students is a growing public health concern. The relationship with friends and family is a major factor associated with selfesteem, resilience, mental health, and psychological selfcare among university students. The findings obtained from this research could be used to initiate intervention strategies to prevent mental health problems. Access to mental health services for university students and social supports by other students and their family members should be promoted. Furthermore, screening for mental health, finding the risks factors for mental health problems, and preventing mental health should be considered among university students, especially among students in the Public Health department. These students are currently studying in the area of health and soon will be the future group of people who work in multidisciplinary teams to provide healthcare services and deal with people with health problems; therefore, the promotion of mental health and well-being of university students should be taken into account. The program should include an online support counseling center, leadership skills training, personal skills development, and ongoing advice and social support from counselors, friends, and family members in order to find effective ways to address and prevent mental health problems.

\section{Ethical Approval and Consent}

The research proposal was reviewed and approved by the Human Research Ethical Committee of University of Phayao (no. 3/024/60). This study was conducted in accordance with the Declaration of Helsinki. The respondents were informed about the objective and the data collection methods of the study, participated benefited potential risk of the study. Informed written consent was received from the participants prior to starting the study. The respondents understood that they could withdraw any time during the interview and had the right to withdraw their consent anytime if they want. All respondents' answers were kept confidential, and survey received data collection form had contained identification number without nametag on it.

\section{Acknowledgments}

We would like to thank all of the university students who participate voluntary and researcher contributions of this project. The author would like to extend their sincere appreciation to University of Phayao for the financial support of this research.

\section{Disclosure}

The authors report no conflicts of interest in this work.

\section{References}

1. Bolinski F, Boumparis N, Kleiboer A, Cuijpers P, Ebert D, Riper H. D, Riper H. The effect of e-mental health interventions on academic performance in university and college students: a meta-analysis of randomized controlled trials. Internet Interventions. 2020;20:1-10. doi:10.1016/j.invent.2020.100321

2. Poorolajal J, Ghaleiha A, Darvishi N, Daryaei S, Panahi S. The prevalence of psychiatric distress and associated risk factors among college students using GHQ-28 questionnaire. Iran J Public Health. 2017;46(7):957-963.

3. Institute for Population and Social Research. Thai Health 2020. Nakhon Pathom Thailand: Mahidol University; 2020. Available from:: https://www.hiso.or.th/hiso/picture/reportHealth/report/ ThaiHealth2020t.pdf. Accessed May 11, 2021.

4. National Statistical Office. The 2018 Survey On Conditions Of Society, Culture and Mental Health. Ministry of Information and Communication Technology; 2020. Available from: http://www.nso. go.th/sites/2014. Accessed May 11, 2021.

5. Ruangkit P, Maneerat S, Meebunmak YA. Study of The Relationships between Mental Health Status and Stress of Nursing Student of Boromarajonani College of Nursing Nopparat Vajira. Veridian E-J Silpakorn Univ Humanities Soc Sci Arts. 2019;12(1):1208-1225.

6. Thanoi W, P A A-Y, Ondee P. Factors Affecting the Mental Health of the Faculty of Nursing Students, Mahidol University. Thai J Nurs Council. 2012;27(special issue):60-76. 
7. Mohamed F, Hamed SA. Prevalence of psychological stress, depression and anxiety among medical students in Egypt. Psychiatry Res. 2017;255:186-194.

8. Thanoi W, Phancharoenworakul K, Thompson E, Panitrat R, Nityasuddhi D. Thai adolescent suicide risk behaviors: testing a model of negative life events, rumination, emotional distress, resilience and social support. Pacific Rim Int J Nurs Res. 2010;14(3):187-202.

9. $\mathrm{Xu} \mathrm{C}$, Gong $\mathrm{X}, \mathrm{Fu} \mathrm{W}$, et al. The role of career adaptability and resilience in mental health problems in Chinese adolescents. Child Youth Serv Rev. 2020;112(104893):1-7.

10. Ratanasiripong P, China T, Toyama S. Mental health and well-being of University Students in Okinawa. Educ Res Int. 2018;2018:1-7. doi: $10.1155 / 2018 / 4231836$

11. Vongsirimas N, Sitthimongkol Y, Beeber SL, Wiratchai N, Sangon S. Relationship among maternal depressive symptoms, gender differences and depressive symptoms in Thai adolescents. Thai J Nurs Res. 2009;13(3):181-198.

12. Smith MJ, Alloy BL, Abramson YL. Cognitive vulnerability to depression, rumination, hopelessness, and suicidal ideation: multiple pathways to self-injurious thinking. Suicide Life Threat Behav. 2006;36(4):443-454.

13. Maslow AH, Frager R, Fadiman J, McReynolds C, Cox R. Motivation and Personality. New York: Harper \& Row; 1970.

14. Teng Z, Liu Y, Guo C. A meta-analysis of the relationship between self-esteem and aggression among Chinese students. Aggress Violent Behav. 2015;21:45-54.

15. Dai CL, Wu MZ, Yang ZL. A research on the relationship and aggressive construct and self-esteem. Psychol Sci. 2006;29(1):44-46.

16. Dray J, Bowman J, Campbell E, et al. Systematic review of universal resilience-focused interventions targeting child and adolescent mental health in the school setting. J Am Acad Child Adolesc Psychiatry. 2017;56(10):813-824.

17. Saito K, Okayasu T. Effects of social skills and self-esteem on resilience in university students. Japanese $J$ Health Psychol. 2014;27(1):12-19.

18. Shi J, Chen Z, Yin F, Zhao J, Zhao X, Yao Y. Resilience as moderator of the relationship between left-behind experience and mental health of Chinese adolescents. Int J Soc Psychiatry. 2016;62 (4):386-393.

19. Hartle MT. Examining the relationships between resilience, mental health and academic persistence in undergraduate college students. $J$ Am Coll Health. 2011;59(7):596-604.

20. Fen Gau SS, Chen YY, Tsai FJ, et al. Risk factors for suicide in Taiwanese college students. J Am Coll Health. 2008;57(2):135-142.

21. Ratanasiripong P, Rodriguez A. Promoting wellness for Thai college students. J Coll Stud Dev. 2011;52(2):217-223.

22. Field T, Diego M, Pelaez M, Deeds O, Delgado J. Depression and related problems in university students. Coll Stud J. 2012;46 (1):193-203

23. Orem DE. Nursing: Concepts of Practice. 3rd ed. New York: McGraw Hill Company; 1985.

24. Rosenberg M. Society and the Adolescent Self-Image. Princeton, NJ: Princeton University Press; 1965.

25. Sunpaweravong J, Noonil N. Mental Health and Psychological Self-care of Undergraduate Nursing Students at Walailak University. Thai J Nurs Council. 2007;22(3):91-104.

26. Kitnopkiat K, Lersthavorntham K, Changkaew W, Yomdit V. Factors Influencing Learning Happiness among Nursing Students, Borommarajonani College of Nursing, Ratchaburi. J Nurs Educ. 2020;13(1):71-82.

27. Cochran WG. Sampling Techniques. New York: John Wiley \& Sons. Inc. Book; 1977.

28. Tinakon W, Nahathai WA. Comparison of Reliability and Construct Validity between the Original and Revised Versions of the Rosenberg Self-Esteem Scale. Psychiatry Investig. 2012;9(1):54-58.
29. Nintacha P, Vanaleesin S, Sanseeha L, Thummatha K, Resilience OP. Thai Youth Risk Behavior. Rama Nurs J. 2011;17(3):430-443.

30. Ito M, Nakajima S, Shirai A, Kim Y. Cross-cultural validity of the Connor-Davidson Scale. The 25th Annual Meeting of the International Society of Traumatic Stress Studies (ISTSS); November 5-7; 2009; Georgia, USA.

31. Nilchaikovit T, Sukying C, Silpakit C. Reliability and validity of the Thai version of the General Health Questionnaire. J Psychiatric Assoc Thailand. 1996;41:2-17.

32. Srisatapor T, Ruamcharoencha T, Boonyapanichkul P, et al. Prevalence of Subjective Health Complaints Among Medical Students, Khon Kaen University. Srinagarind Med J. 2012;27 (3):258-266.

33. Prasongsuk P, Chalittikul W, Badkeaw C, Supaporn S, Chumcheoy S. Factors relating to mental health profile amongst undergraduate students of Public Health Program in Dental Public Health at Sirindhorn College of Public Health Chonburi. Multidisciplinary J Health. 2019;1(1):62-71.

34. Farahangiz S, Mohebpour F, Salehi A. Assessment of Mental Health among Iranian Medical Students: a Cross-Sectional Study. Int J Health Sci (Qassim). 2016;10(1):49-55.

35. Makhal M, Ray PK, Ray Bhattacharya S, Ghosh S, Majumder U, Bandyopadhyay DES. GK, Bera NK. Prevalence of Psychiatric Morbidity Among Undergraduate Students of a Dental College in West Bengal J Clin Diagn Res. 2015;9(7):ZC68-71.

36. Mohebbi Z, Setoodeh G, Torabizadeh C, Rambod M. State of Mental Health and Associated Factors in Nursing Students from Southeastern Iran. Invest Educ Enferm. 2019;37(3):e04.

37. Reverté-Villarroya S, Ortega L, Raigal-Aran L, et al. Psychological Well-Being in nursing students: a multicentric, cross-sectional study. Int J Environ Res Public Health. 2021;18(6):3020.

38. Shi J, Wang L, Yao Y, Su N, Zhao Z, Chen F. Family Impacts on Self-Esteem in Chinese College Freshmen. Front Psychiatry. 2017;8:279

39. Coopersmith S. Self -Esteem Inventory. 2nd ed. California: Consulting Psychologist Press; 1981.

40. Nguyen DT, Wright EP, Dedding C, Pham TT, Bunders J. Low self-esteem and its association with anxiety, depression, and suicidal ideation in vietnamese secondary school students: a cross-sectional study. Front Psychiatry. 2019;10:698.

41. Mulyadia S, Rahardjoa W, Basukia $H$. The role of parent-child relationship, self-esteem, academic self-efficacy to academic stress. Proc Soc Behav Sci. 2016;217:603-608.

42. Busari AO, Atinuke OI. Influence of social media, self-esteem and emotional instability on socio-emotional adjustment of fresh undergraduates of University of Ibadan. Open Access J Neurol Neurosurg. 2019;11(1):001-009.

43. Wongkhan M, Nintachan P, Sangon S. Factors related to resilience adolescents. J Psychiatric Nurs Mental Health. 2015;29 (1):57-75.

44. Collishaw S, Pickles A, Messer J, Rutter M, Shearer C, Maughan B. Resilience to adult psychopathology following childhood maltreatment: evidence from a community sample. Child Abuse Negl. 2007;31:211-229.

45. Ozmen D, Ozmen E, Ergin D, et al. association of self-esteem, depression and body satisfaction with obesity among Turkish adolescents. BMC Public Health. 2007;7(80):1-7.

46. Grotberg EH. Resilience for Today. Westport, CT: Praeger; 2003.

47. Asensio-Martinez A, Olivan-Blazquez B, Montero-Marin J, et al. Relation of the psychological constructs of resilience, mindfulness, and self-compassion on the perception of physical and mental health. Psychol Res Behav Manag. 2019;12:1155-1166.

48. Iamwattanaseri N, Vorakul P, Roomruangwong C. Mental health status and associated factors in first year undergraduate students. Chula Med J. 2017;61(6):83-98. 
49. Suriyentrakorn W, Vittayanont A. Mental health self-esteem of orphans. J Psychiatr Assoc Thailand. 2016;61(2):165-178.

50. Karadag Caman O, Ozcebe H. Adolescents living in orphanages in Ankara: psychological symptoms, level of physical activity, and associated factors. Turk Psikiyatri Derg. 2011;22(2):93-103.

51. Cluver L, Gardner F. Risk and protective factors for psychological well-being of children orphaned by AIDS in Cape Town: a qualitative study of children and caregivers' perspectives. AIDS Care. 2007;19 (3):318-325.

52. Minkprasert A, De Sheng K. A study of mental health and the stress of undergraduate students in Faculty of Pharmacy at Rangsit University. J Soc Sci Hum. 2014;40(2):211-227.
53. Pattyn E, Verhaeghe M, Bracke P. The gender gap in mental health service use. Soc Psychiatry Psychiatr Epidemiol. 2015;50:1089-1095.

54. Richards KC, Campenni E, Muse-Burke J. Self-care and well-being in mental health professionals: the mediating effects of self-awareness and mindfulness. J Mental Health Counseling. 2010;32(3):247-264

55. Pumpuang W. Stress in nursing education: relaxtion techniques for mind and body.. Nurs Sci J Thailand. 2016;34(2):5-15.

\section{Publish your work in this journal}

The Journal of Multidisciplinary Healthcare is an international, peerreviewed open-access journal that aims to represent and publish research in healthcare areas delivered by practitioners of different disciplines. This includes studies and reviews conducted by multidisciplinary teams as well as research which evaluates the results or conduct of such teams or healthcare processes in general. The journal covers a very wide range of areas and welcomes submissions from practitioners at all levels, from all over the world. The manuscript management system is completely online and includes a very quick and fair peer-review system. Visit http://www.dovepress.com/testimonials. php to read real quotes from published authors. 